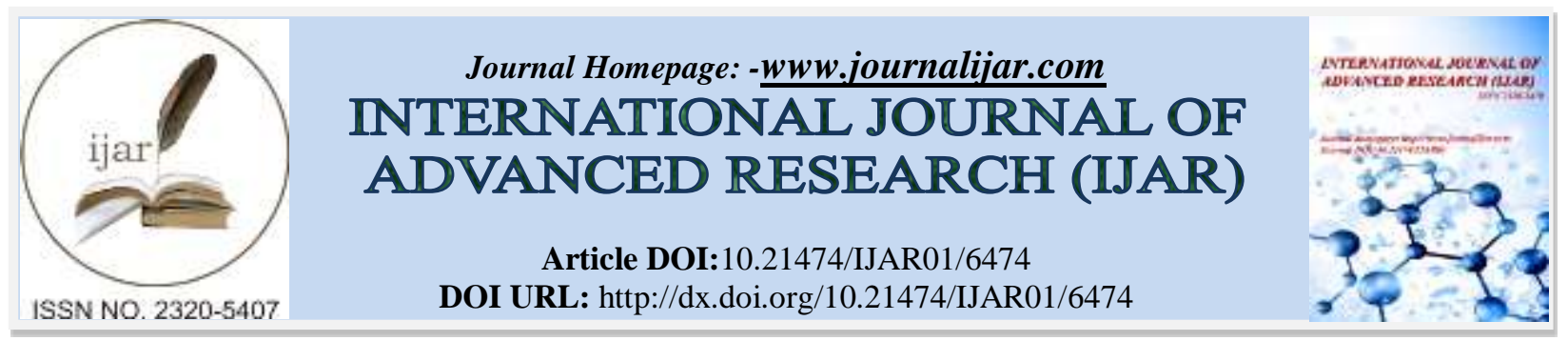

RESEARCH ARTICLE

\title{
CLINICOPATHOLOGICAL STUDY OF UTERINE LEIOMYOMAS IN HYSTERECTOMY SPECIMENS; A RETROSEPTIVE STUDY.
}

\section{Dr. Ph. Priyadarshini ${ }^{1}$ and Dr. Gomathy. $\mathbf{E}^{2}$.}

1. Post graduate student in the Department of Obstetrics and Gynecology, Sri Devraj URs Medical college, Sri Devraj URs Academy of higher Education and Research (SDUAHER), Kolar, Karnataka, India.

2. Professor in the Department of Obstetrics and Gynecology, Sri Devraj URs Medical college, Sri Devraj URs Academy of higher Education and Research (SDUAHER), Kolar, Karnataka, India.

\section{Manuscript Info}

Manuscript History

Received: 08 December 2017

Final Accepted: 10 January 2018

Published: February 2018

Keywords:-

Sponge, Levantine, Mediterranean, Antibacterial Agent, Pathogenic Bacteria.

\section{Abstract}

Introduction: Leiomyomas are the commonly encountered benign uterine neoplasms in women of reproductive age group accounting for $5-20 \%$. We reported 100 cases of women who underwent who hysterectomy for uterine leiyomayomas which was diagnosed by clinically and sonologically.

Methods: This is a retrospective study of 100 cases who underwent hysterectomy for uterine leiyomayomas which was diagnosed by clinically and sonologically between March 2016 to March 2017. Women who underwent hysterectomy with an indication other than for uterine leiyomayomas were excluded in the study. Data including age, parity, symptoms and clinical indication for hysterectomy were collected. Hysterectomy specimens clinically diagnosed as uterine leiomyomas were subjected to histopathological examination. Results: Age range of the patients with leiomyoma was 24-50years. Majority of the patients were between 41-50 years (51\% cases). Menorrhagia was the commonest symptom constituting $38 \%$ cases and fibroid uterus was the most common clinical diagnosis provided (54\%). Most common location of leiomyoma's was intramural $(66.66 \%)$ followed by subserosal $(20.37 \%) \quad 59 \%$ leiomyoma's were single and $41 \%$ were multiple. Degenerative changes were observed in $16.46 \%$ cases, amongst which hyaline change was the most common $(6.33 \%)$. Histopathological patterns showed proliferative endometrium in $66 \%$ and cystic granular hyperplasia in least of $2 \%$ Cystic ovaries were seen in $11 \%$ of the patients, adenomyosis in $19 \%$.

Conclusion: Fibromyoma is the most common benign tumor commonly affects the women of child-bearing age, mostly in the third decade. The most common presentation is menstrual disturbances. Intramural fibroid is the most common variety. The proliferative endometrium, followed by secretary endometrium was commonly reported.

Copy Right, IJAR, 2018,. All rights reserved. 


\section{Introduction:-}

Leiomyomas also known as fibromyomas, fibroids or myomas are the commonly encountered benign uterine neoplasms in women of reproductive age group. They accounts for 5-20\% of all women in reproductive age group (Crum C P, 2004). They need hormonal milieu for their growth and maintenance as evidenced by the molecular studies that leiomyomas which exhibit more estrogen receptors than the normal myometrium (Ackerman,2011). The unopposed estrogenic stimulation manifests commonly as endometrial proliferative phase or hyperplasia (Witherspoon T J, 1993). Fibroids are usually asymptomatic, however depending on their size, location and hormonal effects, the commonest clinical manifestations are presented as menorrhagia, dysmenorrhoea, pain abdomen, mass abdomen and sometimes mass effects (Begum S, 2004). The symptomatic leiomyomas may need urgent attention either by myomectomy in younger women who desirous for retention of childbearing function. However, in elderly women hysterectomy still remains the traditional modality of treatment (Frances Jr H,1995).

Fibroids grossly, are well-circumscribed, firm, gray-white bulging masses (varying in size from barely visible nodules to large tumors that fill the pelvis) that can be easily shelled out from the myometrium. They have a whorled appearance on cut surface with cells arranged in crisscrossing fascicles on microscopy.

The gross appearances are often altered by secondary or degenerative changes. Hyaline degeneration/necrosis is present in more than $60 \%$, particularly in postmenopausal women, and cystic degeneration, myxoid change, fatty degeneration and calcification each occur in about 4\%(Samaila Modupeola OA,2009). After menopause or delivery, leiomyomas can undergo atrophy with significant shrinkage and fibrosis. Red degeneration is associated with pregnancy and contraceptive use, and is due to tumor vessel thrombosis (Zaloudek CJ, 2011).

Worldwide women suffer from gynaecologic and obstetric disorders that require hysterectomy as a treatment modality. Hysterectomy is surgical removal of uterus. a total hysterectomy applies to removal of uterus and cervix. when bilateral adnexae are also removed it is called total hysterectomy with bilateral salpingo-oophorectomy. Radical hysterectomy is more extensive procedure including removal of uterus, cervix, surrounding tissues, upper vagina and pelvic lymph nodes.

Hysterectomy is one of the most commonly performed surgeries in the world (Graves, E j, 1990). In India it accounts for only $6 \%$ of major surgeries (Singh A, 2008). Hysterectomy rate varies from place to place depending upon patient and clinician related factors (Rather GR, 2013). There has been a remarkable improvement in conservative management of uterine lesions; still hysterectomy remains the most preferred modality of treatment for pelvic pathologies like fibroid, adenomyosis, pelvic inflammatory disease and malignant disorder (Nousheen F, 2004) With accurate selection of patients the morbidity and mortality of hysterectomy is low (Abdulla LS, 2006). Prevalence of uterine pathology varies from place to place.

\section{Objectives:-}

1. To find out the most common indication for hysterectomy among rural patients.

2. To analyse various features of clinical and histopathological changes in hysterectomy specimens with uterine leiomyomas

\section{Methods:-}

The present study was conducted in the Dept. of Obstetrics \& Gynaecology and Department of pathology, Sri Devraj Urs Medical College, Kolar, Karnataka, India over a period of one year from March 2016 to March 2017. A total of 100 hysterectomy specimens with or without salphingo-oophorectomy diagnosed clinical and radiologically as uterine leiomyomas were subjected to examination. Patients clinical data was retrieved with respect to age, parity, clinical manifestation, sonographic findings and basis of diagnosis. Women who underwent hysterectomy with an indication other than for uterine leiyomayomas were excluded in the study. On receipt of surgical specimen, they were fixed in $10 \%$ neutral buffered formalin for 24-48 hours. A detailed gross examination of uterus, cervix with or without bilateral adnexae were carried out.

Well circumscribed grey to tan lesions with whorled appearance was considered as leiomyoma and details related to its location, number and secondary changes noted. A minimum of two sections from cervix, endomyometrium and one section each of fallopian tubes and ovaries were taken. And representative additional sections from leiomyomas and other abnormal areas were also taken, processed and paraffin embedded. The blocks were sectioned and stained 
with hematoxylin eosin (H\&E). Data including age, parity, symptoms and clinical indication for hysterectomy were collected. Hysterectomy specimens clinically diagnosed as uterine leiomyomas were subjected to histopathological examination and relevant clinical data were analysed.

\section{Results:-}

The most common indication of hysterectomy between the study period was uterine fibroid being $56 \%$ followed by pelvic organ prolapse constituting $26 \%$.

Table no. 1:- Common indication of hysterectomy.

\begin{tabular}{|l|l|l|}
\hline SL.NO. & Common indication of hysterectomy & Percentage \\
\hline 1. & Uterine fibroid & $54 \%$ \\
\hline 2. & Pelvic organ prolapse & $26 \%$ \\
\hline 3. & Pelvic inflammatory disease & $11 \%$ \\
\hline 4. & Others & $9 \%$ \\
\hline
\end{tabular}

Age:

Table 2: Age wise distribution of the patients with leiomyoma.

\begin{tabular}{|l|l|l|l|}
\hline SL.NO. & $\begin{array}{l}\text { AGE RANGES } \\
\text { (IN YEARS) }\end{array}$ & NO. OF CASES (N=100) & PERCENTAGES (\%) \\
\hline 1. & 21 TO 30 & 4 & $4 \%$ \\
\hline 2. & 31 TO 40 & 45 & $45 \%$ \\
\hline 3. & 41 TO 50 & 51 & $51 \%$ \\
\hline 4. & $>50$ & - & - \\
\hline
\end{tabular}

Age range of the patients with leiomyoma was 24-50years. Majority of the patients were between 41-50 years (51\% cases)

Parity:

Table.no. 3: Parity of the patients with leiomyoma.

\begin{tabular}{|l|l|l|l|}
\hline SL.NO & $\begin{array}{l}\text { PARITY OF PATIENTS WITH } \\
\text { LEIOMYOMA }\end{array}$ & NO. OF CASES (N=100) & PERCENTAGES (\%) \\
\hline 1. & Nulliparous & 3 & $3 \%$ \\
\hline 2. & Primipara & 10 & $10 \%$ \\
\hline 3. & Multipara & 87 & $87 \%$ \\
\hline
\end{tabular}

In this study, majority of leiomyomas were diagnosed in multiparous women. Out of 100 patients with leiomyomas, 87 (87\%) were parous, which includes 14 cases of uniparous patients and only 3 was nulliparous (3\%).

\section{Clinical presentation:-}

Menorrhagia was the commonest symptom constituting $38 \%$ cases, followed by pain in abdomen in $22 \%$ cases and dysmenorrhea in 20 cases (Table 4). Clinical diagnosis by the concerned physician was fibroid uterus in 54\% cases, utero-vaginal prolapse in $26 \%$ cases, and pelvic inflammatory disease in $11 \%$ cases.

Table 4:- Chief complaints of the patients with uterine leiomyoma.

\begin{tabular}{|l|l|l|l|}
\hline SL.NO & CHIEF COMPLAINT & NO. OF CASES (N=100) & PERCENTAGES (\%) \\
\hline 1. & Menorrhagia & 38 & $38 \%$ \\
\hline 2. & Pain in abdomen & 22 & $22 \%$ \\
\hline 3. & Dysmenorrhea & 20 & $20 \%$ \\
\hline 4. & White discharge & 10 & $10 \%$ \\
\hline 5. & Mass per vaginum & 4 & $4 \%$ \\
\hline 6. & Infertility & 4 & $4 \%$ \\
\hline 7. & Asymptomatic & 2 & $2 \%$ \\
\hline
\end{tabular}


Table 5:- Location and number of leiomyoma's in uterus.

\begin{tabular}{|l|l|l|l|}
\hline Sl.no. & $\begin{array}{l}\text { Location of leiomyoma's in } \\
\text { uterus }\end{array}$ & No. Of cases (n=100) & Percentages (\%) \\
\hline 1. & INTRAMURAL & 67 & $67 \%$ \\
\hline 2. & SUBSEROUS & 20 & $20 \%$ \\
\hline 3. & SUBMUCOUS & 11 & $11 \%$ \\
\hline 4. & BROAD LIGAMENT & 2 & $2 \%$ \\
\hline
\end{tabular}

Most common site of leiomyomas was intramural (67\%) followed by subserosal leiomyomas (20\%), submucosal leiomyomas constituted $11 \%$ cases while broad ligament leiomyomas constituted $2 \%$ cases.

In the present study, out of 100 cases of leiomyomas, 59(59\%) were single and 41(41\%) were multiple ( Table no. $6)$.

Table.no.6:- Number of leiomyoma's in the uterus.

\begin{tabular}{|l|l|l|l|}
\hline SL.NO & $\begin{array}{l}\text { NO. OF LEIOMYOMAS'S } \\
\text { IN UTERUS }\end{array}$ & $\begin{array}{l}\text { NO. OF CASES } \\
(\mathbf{N = 1 0 0 )}\end{array}$ & $\begin{array}{l}\text { PERCENTAGES } \\
(\boldsymbol{\%})\end{array}$ \\
\hline 1. & SINGLE & 59 & $59 \%$ \\
\hline 2. & MULTIPLE & 41 & $41 \%$ \\
\hline
\end{tabular}

Table 7:- Various pathological changes seen in uterine leiomyomas.

\begin{tabular}{|l|l|l|l|}
\hline SL.NO. & ENDOMETRIAL PATTERN & $\begin{array}{l}\text { NO. OF CASES } \\
(\mathbf{N = 1 0 0})\end{array}$ & PERCENTAGES (\%) \\
\hline 1. & Proliferative & 66 & $66 \%$ \\
\hline 2. & Secretory & 16 & $16 \%$ \\
\hline 3. & Hyperplasia & 9 & $9 \%$ \\
\hline 4. & Atrophic & 7 & $7 \%$ \\
\hline 5. & Cystic glandular hyperplasia & 2 & $2 \%$ \\
\hline
\end{tabular}

In our study proliferative endometrial pattern is seen in most of the cases constituting $66 \%$ followed by secretory endometrium contributing $16 \%$, the least is seen in cystic glandular hyperplasia in only 2 cases.

Types of leiomyomas: in our study, we observed 66 cases of typical leiomyomas (66\%), followed by leiomyoma variants in 18 cases (18\%) and degenerative changes in 16 cases (16\%).

Degenerative changes were observed in 16 leiomyomas (16\%). Among these, 6 leiomyomas (6\%) showed hyaline change which constituted the most common degenerative change observed in this study, 4 leiomyomas $(4 \%)$ showed myxoid change, 4 cases (4\%) showed calcification, 2 cases (2\%) showed cystic. No cases demonstrated carneous (red) degeneration in our study.

\section{Discussion:-}

The major gynaecological surgery done throughout the world is hysterectomy. Charles Clay was the first to perform subtotal and total hysterectomy in Manchester, England in 1843 and 1929 respectively (Nausheen F, 2004). Hysterectomy is a successful procedure done in terms of symptom relief, patient satisfaction and definitive cure in many disease. Benign conditions like leiomyoma, dysfunction uterine bleeding, adenomyosis, pelvis inflammatory disease, endometriosis, pelvic organ prolapse which account for major hysterectomies and rest for malignancy \{(Gupta S,2006), (Rani S. V. R, 2013)\} Of these benign lesions, leiomyoma followed by adenomyosis are the commonest indication for hysterectomy (Ashraf T, 1997).

The ages of the patients ranged from 24 to 50 years. Highest numbers of patients included in this study were between $41-50$ years $(51 \%)$. These findings were similar to that observed by Gupta et al $(51.40 \%)$, Rather et al (47.27\%), Vaidya et al (45.63\%) and Rizvi et al (44.56\%) \{( Gupta G , 2009), (Rather GM, 2013), (Vaidya S, 2015), (Rizvi G, 2013)\} In other studies, 31-40 years age group was mainly affected like in Karthikeyan et al (46.15\%), Gowri et al (41.3\%) \{ (Karthikeyan TM,2015), (Gowri M,2013)\} 
In this study, menorrhagia was the commonest presenting symptom seen in $38 \%$ cases, followed by dysmenorrhea in $20 \%$ cases. Menorrhagia was also the presenting complaint in studies by Sarfraz (68\%), Karthikeyan (62.5\%), Rather (35.43\%), Gowri (49.03\%) and Manjula K(35.4\%) \{( Sarfraz. R, 2010) (Karthikeyan TM,2015) (Rather GM, 2013) (Gowri M,2013), ( Manjula. K. 2011)\}.

In the present study, out of 100 cases of leiomyomas,59 (59\%) were single and 41(41\%) were multiple. In a study by Sarfraz et al (2010) multiple leiomyomas were seen in $60.87 \%$ cases. ( Sarfraz.R, 2010). Abraham and Saldanha 20 observed solitary leiomyoma in $42.5 \%$ cases and multiple leiomyomas in $57.5 \%$.

The most common site of leiomyomas in our study was intramural (67\%) followed by subserosal leiomyomas $(20 \%)$, sub mucosal leiomyomas $(11 \%)$ and broad ligament leiomyomas (2\%). Jung et al observed intramural fibroids in $55.7 \%$ cases, subserous fibroids in $16.3 \%$ cases, $15.6 \%$, and submucosal fibroids in $12.4 \%$ cases respectively. (Jung. Jk, 1998). Intramural leiomyomas were also the commonest types in studies by Gowri et al (48\%) and Rosario et al (52\%) (Rosario YP, 1968). Abraham and Saldanha observed intramural fibroids in $61.5 \%$ cases, subserosal leiomyomas in 9\% cases and submucosal leiomyomas in 5\% cases (Abraham J,2013).

In the present study, degenerative changes were observed in 16 leiomyomas (16\%). Among these, 6\% showed hyaline change which constituted the most common degenerative change observed in this study, $4 \%$ showed myxoid change, $4 \%$ showed calcification, and none of them have demonstrated red (carneous) degeneration. Jung at al found secondary (degenerative) changes in $9.2 \%$ cases and the most common change was hyaline degeneration $(5.7 \%)$ (Jung. Jk, 1998).

Gowri et al reported secondary changes in $22.6 \%$ cases with hyalinization (16.9\%) being the commonest secondary degenerative changes followed cystic (3.5\%) and myxoid (1.6\%) change (Gowri M,2013).

Abraham and Saldanha observed secondary changes $22.2 \%$ cases; among these $49 \%$ showed hyaline change, $4.9 \%$ showed myxoid change, $4.9 \%$ showed calcification, 3.35 showed red degeneration and $4.9 \%$ showed hydropic changes (Abraham J,2013).

In the present study proliferative phase accounted for $66 \%$ were the commonest endometrial changes seen in association with uterine leiomyomas possibly due to hyper-estrogenic status in accordance with the study by, Purandare et alS, 1993), Sanyal et al ( Sanyal. MK, 1981), Chethana M et al ( Chethana, M, 2013). In the present study atrophic endometrium were $7 \%$ similar to studies by Denligdish et al (Denligdish.L, 1970), Chethana M et al and (Chethana.M, 2013) and described these endometrial changes of normal, hyperplasia and atrophy may be possible due to irregular secretion of estrogens and mechanical effects of fibroid on endometrium.

\section{Conclusion:-}

Fibromyoma is the most common benign tumor of the pelvis. It commonly affects the women of child-bearing age, mostly in the third decade. The most common mode of presentation is menstrual disturbances. Intramural fibroid is the most common variety. The proliferative endometrium, followed by secretary endometrium was commonly reported. The presence of proliferative endometrium, adenomyosis, and cystic ovaries all are indicative of hyperestrogenic state associated with development of fibroids.

\section{Reference:-}

Abraham J, Saldanha P. Morphological variants and secondary changes in uterine leiomyomas. Is it important to recognize them? Int J of Biomed Reseach. 2013;4(12):254-64.

2. Abdulla LS. Hysterectomy: A clinicopathological correlation, Bahrain Medical Bulletin. 2006 June; 28(2):16.

3. Ackerman, Gull B, Karlsson B, Milsom I, Granberg S. Factors associated with endometrial thickness and uterine size in random sample of postmenopausal women. Am J Obstet Gynecol 2001 Aug ; 185(2): 386-91.

4. Ashraf T. Management of uterine leiomyomas. J Coll Physicians Surg Pak 1997;7: 1602.

5. Chethana M,Kumar HML, Munikrishna M. Endometrial Changes in Uterine Leiomyomas. J Clin Biomed Sci $2013 ; 3$ (2).72-79.

6. Crum C P. Body of uterus and Endometrium. In: Kumar V, Abbas A K, Fausto N, Eds. Robbins and Cotran 
Pathologic Basis of Disease. $7^{\text {th }}$ ed. Philadelphia: Saunders, 2004:1089-90.

7. Deligdish L, Loewenthel M. Endometrial changes associated with myomata of the uterus. J Clin Pathol 1970; 23: 676-80.

8. Frances $\mathrm{Jr} \mathrm{H}$. Abdominal myomectomy as a treatment for symptomatic uterine fibroids. Obstetrics and gynecology clinics North-America 1995;22(4):781-9.

9. Gowri M, Mala G, Murthy S, Nayak V. Clinicopathological study of uterine leiomyomas in hysterectomy specimens. Journal of Evolution of Medical and Dental Sciences. 2013;2(46):9002-9.

10. Graves, E j. National centre for health statistics. National Hospital discharge survey. Annual summary, 1990. Viral Health stat (13), 1992, No 112.DHHS publication PHS $92-1773$.

11. Gupta S, Manyonda I. Hysterectomy for benign gynecological diseases. Current Obstet Gynaecol 2006;16:14753. Gupta G, Kotasthane D, Kotasthane V. Hysterectomy: a clinico-pathological correlation of 500 cases. The Internet Journal of Gynecology and Obstetrics. 2009;14(1).

12. Jung JK, Koi MS, Jung BW, Lee HH, Choi HJ, Shin SK. A clinical analysis of uterine myoma. Korean J Obstet Gynecol. 1998;41(1):210-9.

13. Karthikeyan TM, Veenaa NN, Ajeeth Kumar CR, Thomas E. Clinico-pathological study of hysterectomy among rural patients in a tertiary care center. IOSR Journal of Dental and Medical Sciences. 2015;14(5):25-7.

14. Manjula K, Rao KS, Chandrasekhar HR. Variants of Leiomyoma: histomorphological study of tumors of myometrium. Journal of South Asian Federation of Obstetrics and Gynecology. 2011;3(2):89-92.

15. Nausheen F, Iqbal J, Bhatti FA, Khan AT, Sheikh S. Hysterectomy: The patient's perspective. Annals Gynecol

16. $2004 ; 10: 339-41$.

Nousheen F, Iqbal J, Bhatti FA, Sheik S. Hysterectomy The patient perspective. Ann Gynaecol 2004;10:339-41

17. Purandare. S, Jhalam L. Pathological picture in hysterectomy done for abnormal uterine bleeding. J obstet \& Gynacol of India .1993;43:418-21.

18. Rani S. V. R, Thomas S. Leiomyoma, a major cause of abnormal uterine bleeding. J of Evolution of Medical and Dental Sciences.2013;2:2626-30.

19. Rather GR, Gupta Y, Bharadwaj S. Patterns of lesions in hysterectomy specimens; A Prospective study. J.K.Science 2013; 15(2)63-68.

20. Rein MS, Barbieri RL, Friedman AJ. Progesterone: A critical role in pathogenesis of uterine myomas. Am J Obst Gynecol 1995;172(1)14-8.

21. Rizvi G, Pandey H, Pant H, Chufal SS, Pant P. Histopathological correlation of adenomyosis and leiomyoma in hysterectomy specimens as the cause of abnormal bleeding in women in different age groups in the kumaon region-A retrospective study. J of Midlife health.2013;4:27-30.

22. Rosario YP. Uterine fibromyomas. J of Obstet and Gynaecol of India. 1968;18:101-7.

23. Samaila Modupeola OA, Adesiyun AG, Agunbiade OA, Mohammed D. A clinicopathological assessment of hysterectomies in Zaria. Eur J Gen Med. 2009;6(3):150-3.

24. Sanyal MK, Sanyal S, Bhattacharjee KK, Choudari NNK. Clinicopathological study of endometrium. a review of three hundred and twenty cases in different gynaecological abnormalities. J obstet \& Gynacol of India .1981;31:816-21.

25. Sarfraz R, Sarfraz MA, Kamal F, Afsar A. Pattern of benign morphological myometrial lesions in total abdominal hysterectomy specimens. Biomedica. 2010;26:140-3.

26. Singh A, Arora AK. Why Hysterectomy Rate are Lower in India. Indian J Community Med. 2008 Jul; 33(3):196- 7. Vaidya S, Vaidya SA. Patterns of lesions in hysterectomy specimens in a tertiary care hospital. J Nepal Med Assoc. 2015;53(197):18-23.

27. Witherspoon $\mathrm{T} \mathrm{J}$. The interrelationship between ovarian follicle cysts, hyperplasia of the endometrium and

28. fibromyomata. Surg Gynecol Obstet 1933; 56: 1026-35.

Zaloudek CJ, Hendrickson MR, Soslow RA. Mesenchymal tumors of uterus. In: Blaustein Pathology of the female genital tract. $6^{\text {th }}$ ed; 2011:459-466 